\title{
Should Endodontic Residents Be Educated About IV-Sedation? Endodontics Program Directors' and Endodontists' Perspectives
}

\author{
Hassan M. Yehia, Neville McDonald, Sharon Aronovich, Richard Gardner, \\ Marita R. Inglehart
}

Abstract: The aims of the two studies reported here were to assess endodontic postgraduate program directors' educational efforts and attitudes related to educating residents about intravenous (IV) sedation (Study 1) and to assess endodontists' educational experiences and attitudes concerning IV-sedation (Study 2). Directors of all 56 U.S. endodontic residency programs and a sample of 2,173 endodontists in the U.S. were invited to participate in the surveys in 2016 and 2017; 31 directors completed the survey (response rate 55\%), as did 616 endodontists (response rate 28.3\%). Of the participating programs, 18 did not and 13 did offer IV-sedation education. Most directors of programs without this education agreed/strongly agreed that other programs in their institutions offered IV-sedation (83\%) and that none of their faculty were trained to teach it (83\%). Most directors of programs with this education were satisfied/very satisfied with their classroom-based education about IV-sedation (64\%) and this education in general (54\%). Directors of programs with IV-sedation education agreed more strongly than directors of programs without IV-sedation education that there is a need for IV-sedation in endodontics (on five-point scale with 1=disagree strongly: 4.08 vs. $3.39 ; \mathrm{p}=0.05)$, that postgraduate programs should offer it ( $3.50 \mathrm{vs.} 2.71 ; \mathrm{p}=0.04)$, and that many patients inquire about it $(2.75$ vs.1.83; $\mathrm{p}=0.04)$. Most of the endodontists disagreed/disagreed strongly that they had received adequate training in IV-sedation in their postgraduate program (87\%) and were not satisfied with their IV-sedation training (71\%); half (51\%) reported not feeling competent answering patients' questions about IV-sedation. While most of the endodontists were dissatisfied with their IV-sedation related postgraduate education, most of the program directors did not offer IV-sedation education in their programs. A discussion of the need to educate future endodontists about IV-sedation is needed.

\begin{abstract}
Hassan M. Yehia, DDS, MS, is an endodontist in private practice, Dearborn, MI; Neville McDonald, BDS, MS, is Clinical Professor and Director, Endodontics Program, School of Dentistry, University of Michigan; Sharon Aronovich, DMD, FRCD, is Clinical Assistant Professor and Assistant Program Director, Oral and Maxillofacial Surgery Residency Program, University of Michigan Health System; Richard Gardner, DDS, MS, MS, is Adjunct Associate Professor, Department of Cariology, Restorative Sciences, and Endodontics, School of Dentistry, University of Michigan; Marita R. Inglehart, Dr phil habil, is Professor, Department of Periodontics and Oral Medicine, School of Dentistry, and Adjunct Professor, Department of Psychology, College of Literature, Science, and Arts, University of Michigan. Direct correspondence to Dr. Marita R. Inglehart, Department of Periodontics and Oral Medicine, School of Dentistry, University of Michigan, 1011 N. University Street, Ann Arbor, MI 48109-1078; 734-763-8073; mri@umich.edu.
\end{abstract}

Keywords: advanced dental education, endodontics, endodontic postgraduate programs, sedation education, intravenous anesthesia, IV-sedation

Submitted for publication 12/1/17; accepted 1/8/18

doi: 10.21815/JDE.018.077

A ccording to the "Guidelines for the Use of Sedation and General Anesthesia by Dentists" adopted by the American Dental Association (ADA) House of Delegates in October 2016, the "administration of local anesthesia, sedation, and general anesthesia is an integral part of dental practice." ${ }^{\prime \prime}$ Research has found that large percentages of dental patients show their support for this statement when asked about their interest in sedation. For example, $63 \%$ of subjects in a study by Taani preferred local anesthesia to avoid pain, and
$14 \%$ preferred general anesthesia. ${ }^{2}$ Chanpong et al.'s study found that $12.4 \%$ of patients were "definitely interested" in sedation or general anesthesia and $42.3 \%$ were interested dependent upon cost. ${ }^{3}$ These percentages were even higher when patients with high dental fear were surveyed. Considering that $35 \%$ of patients in a study by Wong and Lytle categorized root canal therapy as the most unpleasant treatment and named it in the high anxiety category, ${ }^{4}$ it is not surprising that Huh et al. found that over half of the patients who presented to a Graduate Endodontic 
Clinic for an endodontic consultation would have elected to receive intravenous (IV) sedation for their endodontic treatment if the option was available. ${ }^{5}$ This service is even more advantageous for certain groups of patients such as those with high dental fear and/or a history of a bad dental experience, patients with special medical considerations or mental and developmental conditions, and patients with reflex difficulties. ${ }^{6}$ Ultimately, IV-sedation might result in even more patients seeking and accepting dental and endodontic treatment. ${ }^{7}$

IV-sedation has been found to be safe and effective when used during dental treatment. ${ }^{8}$ But the administration of IV-sedation by dental specialists has been found to be underutilized, thus leaving many patients avoiding the required dental treatment. Research has found that less than $20 \%$ of pediatric dentists administered IV-sedation to their patients, ${ }^{9}$ while $49.8 \%$ of periodontal specialty offices offered the procedure to their patients. ${ }^{10}$ To date, there are no published reports assessing the availability of IV-sedation in endodontists' offices.

One prerequisite of IV-sedation use in endodontists' offices would be that endodontic postgraduate programs ensure that their residents are competent in administering IV-sedation and provide the basis for future endodontists to use it. Strong arguments for including IV-sedation education in endodontic postgraduate programs were provided in 2012 by Montagnese in an opinion article. ${ }^{6}$ This author not only provided an excellent overview of extensive empirical evidence of the need for sedation in endodontics, but also outlined carefully how moderate IV-sedation can be safely and economically incorporated into endodontic practice and should therefore be included in postgraduate endodontic programs' curricula. These supportive arguments for the inclusion of IV-sedation training have been countered by other authors who explored specific concerns such as potential legal implications and litigation, ${ }^{11,12}$ a lack of trained faculty members, ${ }^{13}$ time constraints, ${ }^{6}$ and problems with the availability of equipment.

The lack of empirical evidence concerning the coverage of IV-sedation in endodontic postgraduate programs in the U.S. led to our research. The aims of the two studies reported here were to assess endodontic postgraduate program directors' educational efforts and attitudes related to educating residents about IV-sedation (Study 1) and to assess endodontists' educational experiences and attitudes concerning IV-sedation (Study 2).

\section{Methods}

Institutional Review Board (IRB) approval was obtained for these two studies from the IRB for the Health Sciences and Behavioral Sciences at the University of Michigan. Both studies were determined to be exempt from IRB oversight because all survey responses were anonymous (\#HUM00116078; Date of Notification: June 24, 2016). Study 1 was a survey of directors of U.S. endodontic postgraduate programs. Study 2 was a survey of practicing endodontists in the U.S. who were all members of the American Association of Endodontists (AAE).

In Study 1, recruitment emails were sent to the directors of all 56 endodontic residency programs in the U.S. at the time. The directors were contacted with a first email by the program director of the Endodontic Graduate Program at the University of Michigan School of Dentistry in July 2016, with a second follow-up email in October 2016. One additional contact was made starting in January 2017 with the non-responding programs by the principal investigator (PI: HMY) of this study. The email explained the purpose of the study and asked the program directors to respond to an anonymous survey by using a weblink in the email that connected them to the survey. The follow-up emails were sent to encourage participation.

In Study 2, prior to distributing surveys to the endodontists, an a priori power analysis with the program package $G^{*}$ Power 3.1.2 (www.psycho. uni-duesseldorf.de/abteilungen/aap/ gpower3) was conducted to determine the sample size needed to have the power to test hypotheses about relationships between responses. It was assumed that alpha $=0.05$, power $=0.80$, small effect size of rho $=0.12$, when using one-sided tests to test for the significance of correlations. The results showed that 425 respondents were required to have the power to test such a hypothesis. A mailing list of AAE members was purchased from the AAE, and assuming a response rate of $20 \%$, we randomly selected 2,224 address labels from the list of 3,706. The surveys were mailed out via postal mail between March 25 and April 30, 2017. The respondents received a large envelope that contained the survey, a cover letter from the program director of the Endodontic Graduate Program at the University of Michigan School of Dentistry, and a stamped self-addressed return envelope. The letter explained the research and asked for the recipients' cooperation with responding to the mailed survey. 
The respondents returned the survey anonymously to the PI in the envelope provided. Due to financial constraints, only one mailing was possible.

The survey for the program directors was based on a literature review of questionnaires concerning IV-sedation coverage in dental schools ${ }^{14-17}$ and residency programs. ${ }^{5,9,13,18}$ The draft survey was pilot tested with the program director of the Endodontic Graduate Program at the University of Michigan School of Dentistry. His feedback was used to finalize the survey.

This survey had four parts. Part I asked respondents for information about their program and postgraduate students. Part II was directed only to program directors who did not educate their residents about IV-sedation. These directors were asked in six multiple-choice questions about their level of agreement with statements about why they did not offer IV-sedation education (response options from $1=$ disagree strongly to $5=$ agree strongly). Openended questions asked about additional reasons for not offering this material, and a final question asked if they were planning to add this type of education to the program in the future. Part III was directed only to directors of programs that did provide IVsedation education. This section began with eight multiple-choice questions concerning reasons why the program educated its residents about IV-sedation (with the same five-point response scale). In addition to these closed-ended questions, these directors were asked how many years their programs had offered IV-sedation, if this education was optional or required for residents, how many hours of classroom-based IV-sedation education their program offered, and whether their tuition had been increased due to IV-sedation being taught in their program. Part IV of the survey consisted of 14 multiple-choice questions with statements about IV-sedation related to postgraduate education and clinical practice. In addition, multiple-choice questions asked how much patients with non-surgical root canal therapy, surgical endodontic therapy, implants, and extraction would want IV-sedation. The response scale ranged from $1=$ no demand at all to $5=$ very high demand.

The survey for the endodontists was based on a literature review of studies with dentists ${ }^{11,17,19,20}$ and dental specialists ${ }^{6,9,10}$ concerning IV-sedation. The draft survey was pilot tested with six endodontists in December 2016 to January 2017. Feedback was considered, and a final version of the survey was developed. This survey included background questions asking for respondents' gender, age, and educational background. Six questions asked how well the endodontists perceived their postgraduate endodontics education had educated them about IV-sedation, how satisfied they were with their IV-sedation training after completion of their postgraduate program, if they wanted more training, and if they already took or wanted to take continuing education classes about IV-sedation in the future. A final question asked them how competent they felt answering patient questions concerning IV-sedation. These two sets of six questions had five-point response scales from $1=$ disagree strongly to $5=$ agree strongly.

In Study 1, the data were exported from the University of Michigan UM Lessons website as an Excel file and imported into SPSS, Version 22 (IBM Corp., Armonk, NY, USA). In Study 2, the postal mailed survey responses were entered into SPSS, Version 22. For both studies, descriptive statistics such as frequencies, percentages, means, and standard deviation were computed to provide an overview of the responses. In Study 1, inferential statistics, specifically independent sample t-tests, were used to compare the average responses of the program directors who offered versus who did not offer IVsedation education. In Study 2, inferential statistics were used to determine whether Pearson correlation coefficients were significant. A significance level of $\mathrm{p}<0.05$ was used.

\section{Results}

Directors of 31 of the 56 endodontic residency programs completed the survey (55\% response rate). Of the 2,224 AAE members invited to participate in the endodontists survey, 51 envelopes were returned as undeliverable due to address problems, resulting in 2,173 possible participants. Responses were obtained from 616 endodontists, for a response rate of $28.3 \%$.

\section{Program Directors Survey}

The 31 participating programs were in 21 states, as compared to the 30 states in which the total 56 endodontic programs are located. Of the 31 participating programs, 26 were located at a dental school, four were armed services-related programs, and one was hospital-based (Table 1). Four programs granted only a certificate, seven only a master's degree, and 19 both a certificate and a master's degree. Twenty programs were located in a large city, eight in a moderate-sized city, and three in suburbs near a large city. The average number of graduates per 
year ranged from two to eight (Mean=3.67). These programs were 24 to 36 months long. The number of full-time clinical instructors in each ranged from one to eight $($ Mean=3.03) and the number of part-time clinical instructors from 0 to 20 (Mean=7.77). On average, patients treated by residents were covered by fee for service (35\%), dental insurance $(29 \%)$, or Medicaid (25\%).

Table 2 provides an overview of responses of the 18 directors whose programs did not educate their residents about IV-sedation. When asked why they did not provide this service, a third agreed/agreed strongly with the statement "Future endodontists do not need to be able to provide IV-sedation" and 28\% that "Patients do not need IV-sedation for endodontic treatment." Among these respondents, 83\% agreed/ strongly agreed both that other programs in their institution provided this service and that none of their faculty was certified in IV-sedation. Also, 39\% agreed/strongly agreed that there was not enough time during the program to offer IV-sedation education and a third that they did not have the facilities to safely provide IV-sedation.

In response to an open-ended question about other reasons for not providing this type of education, three directors answered that IV-sedation is not safe while working with a microscope. Two directors reported that longer appointment times would be needed, that legal barriers/liability issues were involved, and that oral sedation is an adequate replacement for IV-sedation. Two of the directors (11\%) said their programs planned to add IV-sedation education in the future, five said they may add it (28\%), and 11 $(61 \%)$ did not plan to add it in the future.

Table 3 shows responses of directors of the 13 programs with IV-sedation education. In these programs, IV-sedation education had been offered for one to 39 years (Mean=10 years), and classroombased IV-sedation education hours ranged from two to 60 hours (Mean=21.5 hours). Seven programs (54\%) made IV-sedation education optional, and six required it. All of these directors agreed that tuition had not increased due to IV-sedation education and that no minimum number of patients with IV-sedation was required. Just over half (54\%) were satisfied with their classroom-based education about IV-sedation and the way IV-sedation was taught in their residency program. However, only $30 \%$ strongly agreed that they had excellent faculty to instruct their students about IV-sedation. While $42 \%$ agreed/strongly agreed that future endodontists needed to be able to provide IV-sedation, only $25 \%$ responded that their residents
Table 1. Characteristics of endodontic residency programs in study, by number and percentage of participating programs ( $\mathrm{N}=31)$ and by mean and standard deviation (range)

\begin{tabular}{|c|c|c|}
\hline Characteristic & Number & Percentage \\
\hline \multicolumn{3}{|l|}{ Program location } \\
\hline Dental school & 26 & $87 \%$ \\
\hline Armed services & 4 & $13 \%$ \\
\hline Hospital-based & 1 & $3 \%$ \\
\hline \multicolumn{3}{|l|}{ Degree granted (all that apply) } \\
\hline Certificate & 23 & $74 \%$ \\
\hline Master's degree & 26 & $84 \%$ \\
\hline $\mathrm{PhD}$ & 2 & $7 \%$ \\
\hline MPH, Med, MTS & 1 & $3 \%$ \\
\hline $\mathrm{DScD}$ & 1 & $3 \%$ \\
\hline \multicolumn{3}{|l|}{ Location of program } \\
\hline Rural $(<5,000)$ & 0 & - \\
\hline Small town/city $(5,000-24,999)$ & 0 & - \\
\hline Moderate-sized city $(25,000-250,000)$ & 8 & $26 \%$ \\
\hline Suburb near large city & 3 & $10 \%$ \\
\hline \multirow[t]{2}{*}{ Large city } & 20 & $65 \%$ \\
\hline & Mean & SD (Range) \\
\hline Average number of graduates per year & 3.67 & $1.373(2-8)$ \\
\hline Program length in months & 26.10 & $3.716(24-36)$ \\
\hline \multicolumn{3}{|l|}{ Number of clinical instructors } \\
\hline Full-time & 3.03 & $1.622(1-8)$ \\
\hline Part-time & 7.77 & $6.409(0-20)$ \\
\hline \multicolumn{3}{|l|}{ Number of patients per week } \\
\hline$<18$ years of age & 7.52 & $8.517(0-36)$ \\
\hline Adults & 35.78 & $22.723(1-90)$ \\
\hline \multicolumn{3}{|l|}{$\%$ patients treated by residents covered by } \\
\hline Medicaid & $25 \%$ & $19.222(0-65)$ \\
\hline Insurance & $29 \%$ & $24.836(0-80)$ \\
\hline Fee for service & $35 \%$ & $27.895(0-90)$ \\
\hline Other & $11 \%$ & $27.05(0-100)$ \\
\hline
\end{tabular}

had sufficient clinical experiences to be competent in administering IV-sedation. Only 18\% reported that their residents were confident about administering IV-sedation and that most residents incorporated IV-sedation in their practice, and only $16 \%$ agreed/ strongly agreed that residents were motivated to learn about IV-sedation.

The average responses of directors of programs with vs. without IV-sedation education differed significantly (Figure 1). Directors of programs with IV-sedation education agreed more strongly with the statement that there is a need for IV-sedation in endodontics ( 4.08 vs. $3.39 ; \mathrm{p}=0.05$ ) and that postgraduate programs should offer IV-sedation training to residents ( 3.50 vs. $2.71 ; p=0.04)$ than directors of 
Table 2. Responses of endodontic residency directors whose programs did not educate residents about IV-sedation ( $\mathrm{N}=18$ )

\begin{tabular}{|c|c|c|c|c|c|c|}
\hline Statement & 1 & 2 & 3 & 4 & 5 & $\begin{array}{c}\text { Mean } \\
\text { SD }\end{array}$ \\
\hline Future endodontists do not need to be able to provide IV-sedation. & $6 \%$ & $17 \%$ & $44 \%$ & $22 \%$ & $11 \%$ & $\begin{array}{c}3.17 \\
1.043\end{array}$ \\
\hline Patients do not need IV-sedation for endodontic treatment. & $11 \%$ & $22 \%$ & $39 \%$ & $17 \%$ & $11 \%$ & $\begin{array}{c}2.94 \\
1.162\end{array}$ \\
\hline Other programs in our institution provide this service. & $6 \%$ & $6 \%$ & $6 \%$ & $11 \%$ & $72 \%$ & $\begin{array}{c}4.39 \\
1.195\end{array}$ \\
\hline None of our endodontic faculty is certified in IV-sedation. & 0 & $11 \%$ & $6 \%$ & $33 \%$ & $50 \%$ & $\begin{array}{c}4.22 \\
1.003\end{array}$ \\
\hline There is not enough time during our program to teach IV-sedation. & $6 \%$ & $22 \%$ & $33 \%$ & $22 \%$ & $17 \%$ & $\begin{array}{c}3.22 \\
1.166\end{array}$ \\
\hline We do not have the facilities to safely provide IV-sedation. & $39 \%$ & $11 \%$ & $17 \%$ & $22 \%$ & $11 \%$ & $\begin{array}{c}2.56 \\
1.604\end{array}$ \\
\hline
\end{tabular}

Note: Response options were 1=disagree strongly, 2=disagree, 3=neutral, 4=agree, and 5=agree strongly. Open-ended responses for reasons programs did not provide IV-sedation education were as follows: Longer residency program needed, Not safe while working with microscope, No faculty currently trained adequately to oversee clinical cases (3 respondents each); Longer appointments needed, IV-sedation not needed in endo, Legal barriers/liability, Oral sedation sufficient, Facility upgrade would be needed (2 respondents each); and Only needed for pediatric patients, Cases would become inefficient, Equipment upgrade needed, Residents work with anesthesiologist who administers it (1 respondent each).

Table 3. Responses of endodontic residency directors whose programs did educate residents about IV-sedation ( $\mathrm{N}=13)$

\begin{tabular}{|c|c|c|c|c|c|c|}
\hline Statement & 1 & 2 & 3 & 4 & 5 & $\begin{array}{l}\text { Mean } \\
\text { SD }\end{array}$ \\
\hline \multicolumn{7}{|l|}{ Satisfaction with IV-sedation education } \\
\hline $\begin{array}{l}\text { I am very satisfied with the classroom-based education we } \\
\text { provide for our residents about IV-sedation. }\end{array}$ & 0 & 0 & $36 \%$ & $55 \%$ & $9 \%$ & $\begin{array}{l}3.73 \\
0.647\end{array}$ \\
\hline $\begin{array}{l}\text { I am very satisfied with the way IV-sedation is taught in our } \\
\text { residency program. }\end{array}$ & 0 & $9 \%$ & $36 \%$ & $36 \%$ & $18 \%$ & $\begin{array}{c}3.64 \\
0.924\end{array}$ \\
\hline $\begin{array}{l}\text { We have excellent faculty to instruct our students about } \\
\text { IV-sedation. }\end{array}$ & 0 & $20 \%$ & $50 \%$ & 0 & $30 \%$ & $\begin{array}{c}3.40 \\
1.174\end{array}$ \\
\hline \multicolumn{7}{|l|}{ Outcomes of IV-sedation education } \\
\hline $\begin{array}{l}\text { Future endodontists need to be able to provide } \\
\text { IV-sedation. }\end{array}$ & $8 \%$ & $8 \%$ & $42 \%$ & $17 \%$ & $25 \%$ & $\begin{array}{c}3.42 \\
1.240\end{array}$ \\
\hline Residents are motivated to learn about IV-sedation. & 0 & $17 \%$ & $67 \%$ & $8 \%$ & $8 \%$ & $\begin{array}{c}3.08 \\
0.793\end{array}$ \\
\hline $\begin{array}{l}\text { Upon graduation, most residents incorporate IV-sedation } \\
\text { in their practice. }\end{array}$ & $27 \%$ & $27 \%$ & $27 \%$ & $18 \%$ & 0 & $\begin{array}{c}2.36 \\
1.120\end{array}$ \\
\hline $\begin{array}{l}\text { Our residents have sufficient clinical experiences to be } \\
\text { competent in administering IV-sedation. }\end{array}$ & $42 \%$ & $25 \%$ & $8 \%$ & $17 \%$ & $8 \%$ & $\begin{array}{l}2.25 \\
1.422\end{array}$ \\
\hline Our graduates are confident about administering IV-sedation. & $36 \%$ & $36 \%$ & $9 \%$ & $18 \%$ & 0 & $\begin{array}{c}2.09 \\
1.136\end{array}$ \\
\hline
\end{tabular}

Note: Response options were $1=$ disagree strongly, $2=$ disagree, $3=$ neutral, $4=$ agree, and $5=$ agree strongly. Percentages may not total $100 \%$ because of rounding.

programs without this education. However, directors of programs without IV-sedation agreed more strongly that IV-sedation was expensive for patients (4.06 vs. $3.33 ; p=0.03)$ and on average disagreed more that many patients inquired about IV-sedation for their endodontic treatment ( 1.83 vs. $2.75 ; \mathrm{p}=0.04$ ). However, the two groups of directors did not differ in their average responses to most patientrelated statements and the statements concerning problems related to providing IV-sedation education (Table 4). For example, both groups agreed on average that many patients were fearful/apprehensive when presenting for endodontic treatment, that finding competent instructors to teach IV-sedation and the maintenance of IV-sedation equipment were challenges, and that IV-sedation training had a lot of liability. 


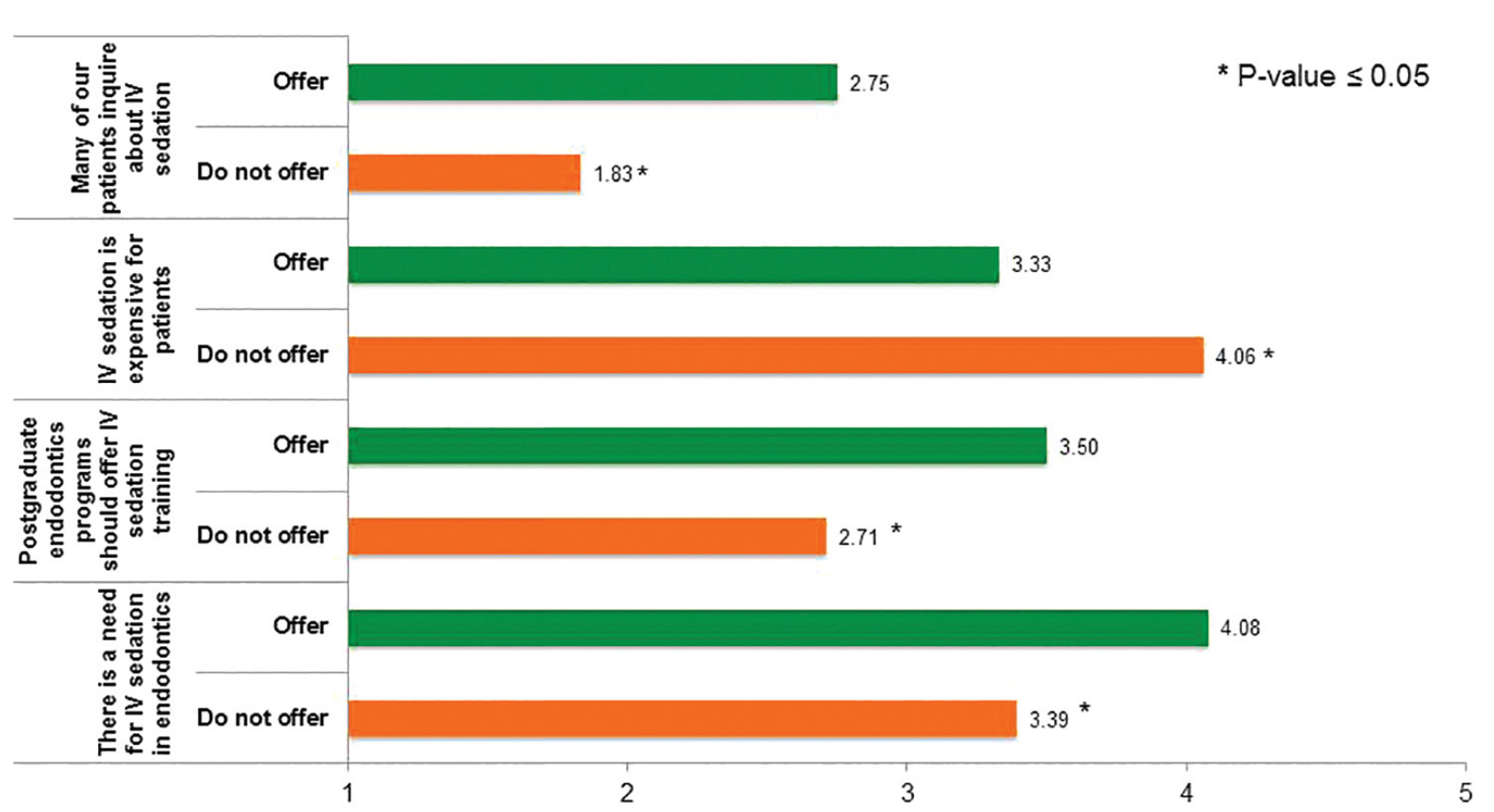

Figure 1. Comparison of IV-sedation related attitudes of program directors that did vs. did not offer IV-sedation education

Note: Numbers on $\mathrm{x}$-axis range from $1=$ disagree strongly to $5=$ agree strongly.

\section{Endodontists Survey}

These 616 respondents had graduated from 61 dental schools in the U.S. and from 17 dental schools outside the U.S. They had attended 69 endodontic residency programs, and their year of graduation ranged from 1962 to 2016. Most had received a certificate $(91 \%), 33 \%$ had received a master's degree, and seven had obtained a Ph.D. The length of their endodontic postgraduate programs ranged from ten to 60 months (Mean=25 months).

Table 5 shows these endodontists' responses concerning IV-sedation education during their postgraduate program and after completing their program. Only $10 \%$ agreed/strongly agreed that they had received adequate training in IV-sedation, while $77 \%$ strongly disagreed with this statement. In addition, $17 \%$ agreed/strongly agreed that they had received classroom-based education and $9 \%$ that they had received clinical training in IV-sedation. Only $6 \%$ agreed/strongly agreed that IV-sedation training was a required part of their program, and $6 \%$ had performed a minimum number of IV-sedation procedures on patients.

Six questions asked for the endodontists' perceptions concerning education on this topic after completing their postgraduate program. Only $15 \%$ agreed/strongly agreed that they were satisfied with their postgraduate training in IV-sedation; $65 \%$ strongly disagreed with that statement. While 33\% agreed/strongly agreed that they wished they had more training in IV-sedation, $25 \%$ said they felt competent answering patients' questions about it. Only $6 \%$ agreed/strongly agreed that they felt comfortable performing IV-sedation on their patients. Approximately $10 \%$ had taken continuing education classes about IV-sedation, and 17\% agreed/strongly agreed they would like to take more continuing education classes on this subject.

The far right column of Table 5 shows the relationships between these endodontists' answers and their age. The older the endodontists were, the more likely they were to agree with the statements that they had received clinical training in IV-sedation $(\mathrm{r}=0.15$; $\mathrm{p}<0.001)$, that IV-sedation education had been a required part of their postgraduate program $(\mathrm{r}=0.08$; $\mathrm{p}<0.05$ ), and that they felt comfortable performing IV-sedation $(r=0.15 ; \mathrm{p}<0.001)$. However, the older the respondents were, the less they agreed that they would like to take more continuing education classes about IV-sedation $(\mathrm{r}=-0.17 ; \mathrm{p}<0.001)$. 
Table 4. Participating program directors' perspectives about IV-sedation education expressed as mean (standard deviation)

\begin{tabular}{|c|c|c|c|c|}
\hline \multirow[b]{2}{*}{ Statement } & \multicolumn{2}{|c|}{ IV-Sedation Education } & \multirow[b]{2}{*}{ p-value } & \multirow[b]{2}{*}{ Total Programs $(\mathrm{N}=31)$} \\
\hline & No $(\mathrm{N}=18)$ & Yes $(N=13)$ & & \\
\hline There is a need for IV-sedation in endodontics. & $\begin{array}{c}3.39 \\
(0.979)\end{array}$ & $\begin{array}{c}4.08 \\
(0.793)\end{array}$ & 0.05 & $\begin{array}{c}3.67 \\
(0.959)\end{array}$ \\
\hline $\begin{array}{l}\text { Postgraduate endodontic programs should offer IV-sedation } \\
\text { training to residents. }\end{array}$ & $\begin{array}{c}2.71 \\
(1.047)\end{array}$ & $\begin{array}{c}3.50 \\
(0.905)\end{array}$ & 0.04 & $\begin{array}{c}3.03 \\
(1.052)\end{array}$ \\
\hline \multicolumn{5}{|l|}{ Patient-related considerations } \\
\hline IV-sedation is expensive for patients. & $\begin{array}{c}4.06 \\
(0.539)\end{array}$ & $\begin{array}{c}3.33 \\
(0.985)\end{array}$ & 0.03 & $\begin{array}{c}3.77 \\
(0.817)\end{array}$ \\
\hline $\begin{array}{l}\text { Many patients are fearful/apprehensive when presenting for } \\
\text { endodontic treatment. }\end{array}$ & $\begin{array}{l}3.56 \\
(0.784)\end{array}$ & $\begin{array}{c}3.40 \\
(1.075)\end{array}$ & n.s. & $\begin{array}{l}3.50 \\
(0.882)\end{array}$ \\
\hline $\begin{array}{l}\text { IV-sedation is only needed for patients with special health } \\
\text { care needs. }\end{array}$ & $\begin{array}{l}3.33 \\
(0.970)\end{array}$ & $\begin{array}{l}2.75 \\
(1.357)\end{array}$ & n.s. & $\begin{array}{l}3.10 \\
(1.155)\end{array}$ \\
\hline $\begin{array}{l}\text { All patients should have a choice to have their treatment } \\
\text { under IV-sedation. }\end{array}$ & $\begin{array}{c}3.06 \\
(1.162)\end{array}$ & $\begin{array}{c}2.92 \\
(1.240)\end{array}$ & n.s. & $\begin{array}{c}3.00 \\
(1.174)\end{array}$ \\
\hline $\begin{array}{l}\text { Offering IV-sedation to patients will increase treatment } \\
\text { acceptance. }\end{array}$ & $\begin{array}{l}2.83 \\
(0.985)\end{array}$ & $\begin{array}{l}2.83 \\
(0.937)\end{array}$ & n.s. & $\begin{array}{c}2.83 \\
(0.950)\end{array}$ \\
\hline $\begin{array}{l}\text { Many of our patients inquire about IV-sedation for their } \\
\text { endodontic treatment. }\end{array}$ & $\begin{array}{c}1.83 \\
(0.857)\end{array}$ & $\begin{array}{c}2.75 \\
(1.288)\end{array}$ & 0.04 & $\begin{array}{c}2.20 \\
(1.126)\end{array}$ \\
\hline \multicolumn{5}{|l|}{ Problems related to providing IV-sedation education } \\
\hline $\begin{array}{l}\text { Having competent staff to support IV-sedation is a } \\
\text { challenge. }\end{array}$ & $\begin{array}{c}4.22 \\
(0.732)\end{array}$ & $\begin{array}{c}3.58 \\
(1.240)\end{array}$ & n.s. & $\begin{array}{l}3.97 \\
(0.999)\end{array}$ \\
\hline IV-sedation training has a lot of liability. & $\begin{array}{c}3.94 \\
(0.802)\end{array}$ & $\begin{array}{c}3.75 \\
(1.357)\end{array}$ & n.s. & $\begin{array}{c}3.87 \\
(1.042)\end{array}$ \\
\hline $\begin{array}{l}\text { Finding competent instructors to teach IV-sedation } \\
\text { is a challenge. }\end{array}$ & $\begin{array}{c}3.83 \\
(0.924)\end{array}$ & $\begin{array}{c}3.75 \\
(1.138)\end{array}$ & n.s. & $\begin{array}{c}3.80 \\
(0.997)\end{array}$ \\
\hline Maintenance of IV-sedation equipment is a challenge. & $\begin{array}{l}3.56 \\
(0.856)\end{array}$ & $\begin{array}{c}3.42 \\
(1.311)\end{array}$ & n.s. & $\begin{array}{c}3.50 \\
(1.042)\end{array}$ \\
\hline $\begin{array}{l}\text { IV-sedation training is expensive for an endodontic } \\
\text { residency program. }\end{array}$ & $\begin{array}{c}3.71 \\
(0.985)\end{array}$ & $\begin{array}{c}3.17 \\
(1.337)\end{array}$ & n.s. & $\begin{array}{c}3.48 \\
(1.153)\end{array}$ \\
\hline \multicolumn{5}{|l|}{ Demand for IV-sedation when patients have } \\
\hline Non-surgical root canal therapy & 2.31 & 2.27 & n.s. & 2.30 \\
\hline Surgical endodontic therapy & 3.00 & 2.64 & n.s. & 2.85 \\
\hline Implants & 2.79 & 2.90 & n.s. & 2.83 \\
\hline Extractions & 2.86 & 2.89 & n.s. & 2.87 \\
\hline
\end{tabular}

Note: Response options were either $1=$ disagree strongly, $2=$ disagree, $3=$ neutral, $4=$ agree, and $5=$ agree strongly or, on the bottom item, from $1=$ no demand at all to $5=$ very high demand.

n.s.=not significant

\section{Discussion}

Over half of the 56 directors of endodontic residency programs in the U.S. responded to this web-based survey. Given the frequently low response rates to web-based surveys, ${ }^{21}$ this $55 \%$ response rate is acceptable. The results offer an opportunity to explore the considerations of directors of programs that did vs. did not offer IV-sedation. The two most frequently named reasons for not providing this education were that other programs in their institution offered this service and that there was a lack of endodontic faculty certified in IV-sedation. The role of trained faculty members as a determining issue for providing IV-sedation was also mentioned by Setty et al., who surveyed moderate sedation protocols in specialty programs in the U.S. in $2014 .{ }^{13}$ However, so far no research has explored interprofessional interactions related to providing IV-sedation between endodontic residents and faculty members or clinicians from other programs in an institution. Gaining a better understanding of how these collaborations are structured and how much instruction endodontic residents receive during these interactions would be helpful in identifying best practices that other programs could introduce. Future research should therefore explore these possibilities. 


\begin{tabular}{|c|c|c|c|c|c|c|c|}
\hline Statement & 1 & 2 & 3 & 4 & 5 & $\begin{array}{l}\text { Mean } \\
\text { SD }\end{array}$ & $\underset{r}{\text { Age }}$ \\
\hline \multicolumn{8}{|l|}{ During my postgraduate program } \\
\hline I received classroom-based education about IV-sedation. & $57 \%$ & $13 \%$ & $13 \%$ & $7 \%$ & $10 \%$ & $\begin{array}{c}2.00 \\
1.372\end{array}$ & -0.01 \\
\hline I received clinical training in IV-sedation. & $77 \%$ & $10 \%$ & $5 \%$ & $3 \%$ & $6 \%$ & $\begin{array}{c}1.53 \\
1.122\end{array}$ & $0.15^{* *}$ \\
\hline I received adequate training in IV-sedation. & $77 \%$ & $10 \%$ & $4 \%$ & $4 \%$ & $6 \%$ & $\begin{array}{c}1.51 \\
1.103\end{array}$ & 0.08 \\
\hline IV-sedation training was only offered as an elective. & $78 \%$ & $5 \%$ & $6 \%$ & $4 \%$ & $7 \%$ & $\begin{array}{c}1.57 \\
1.210\end{array}$ & -0.00 \\
\hline IV-sedation training was a required part of my program. & $85 \%$ & $5 \%$ & $4 \%$ & $2 \%$ & $4 \%$ & $\begin{array}{c}1.35 \\
0.964\end{array}$ & $0.08^{*}$ \\
\hline I had to perform a minimum number of IV-sedations on patients. & $89 \%$ & $4 \%$ & $2 \%$ & $1 \%$ & $5 \%$ & $\begin{array}{c}1.28 \\
0.954\end{array}$ & 0.05 \\
\hline \multicolumn{8}{|l|}{ Upon completion of my postgraduate program } \\
\hline I was overall satisfied with my training in IV-sedation. & $65 \%$ & $7 \%$ & $13 \%$ & $7 \%$ & $8 \%$ & $\begin{array}{l}1.86 \\
1.325\end{array}$ & 0.00 \\
\hline I took continuing education (CE) classes about IV-sedation. & $75 \%$ & $9 \%$ & $7 \%$ & $4 \%$ & $6 \%$ & $\begin{array}{c}1.57 \\
1.146\end{array}$ & $0.10^{*}$ \\
\hline I wish I had had more training in IV-sedation. & $37 \%$ & $11 \%$ & $19 \%$ & $12 \%$ & $21 \%$ & $\begin{array}{c}2.70 \\
1.566\end{array}$ & -0.04 \\
\hline I would like to take more CE classes about IV-sedation. & $55 \%$ & $11 \%$ & $17 \%$ & $7 \%$ & $10 \%$ & $\begin{array}{c}2.07 \\
1.388\end{array}$ & $-0.17 * *$ \\
\hline I feel competent answering patient questions concerning IV-sedation. & $40 \%$ & $12 \%$ & $24 \%$ & $13 \%$ & $11 \%$ & $\begin{array}{l}2.45 \\
1.410\end{array}$ & 0.03 \\
\hline I feel comfortable performing IV-sedation on my patients. & $82 \%$ & $6 \%$ & $6 \%$ & $2 \%$ & $4 \%$ & $\begin{array}{c}1.39 \\
0.953\end{array}$ & $0.15^{* *}$ \\
\hline
\end{tabular}

Note: Response options were $1=$ disagree strongly, $2=$ disagree, $3=$ neutral, $4=$ agree, and $5=$ agree strongly. "Age" column shows Pearson correlation coefficients between age and the response. Percentages may not total $100 \%$ because of rounding.

${ }^{*} \mathrm{p}<0.05 ;{ }^{* *} \mathrm{p}<0.001$

One interesting finding concerning the responses of directors who did not educate their residents about IV-sedation is the fact that only $33 \%$ agreed/strongly agreed that future endodontists need to be able to provide IV-sedation. Similarly, only $42 \%$ of the directors who did offer IV-sedation education indicated that future endodontists need to be able to provide IV-sedation. These findings differed from the results that Morse et al. reported based on their surveys of dental education programs in Japan. ${ }^{17}$ Those authors found that $71 \%$ of the dental schools did not provide education about IV-sedation for future general dental practitioners. However, among those respondents, the majority $(76 \%)$ believed that it was important to provide IV-sedation education and training in dental schools, and 70\% answered that IV-sedation services were not used enough in private general dental practices.

Of the programs surveyed in our study, 13 offered IV-sedation education, with one program having offered it for the past 39 years. The program directors' reasoning concerning a need for this type of service was more in line with the arguments presented by Montagnese in 2012 in an opinion piece describing the value of moderate IV-sedation education in endodontic residency programs. ${ }^{6}$ Other research also provides support for the belief that endodontists need to provide IV-sedation for their patients because patients are afraid of endodontic treatment. In 1991, Wong and Lytle reported that $35 \%$ of participating patients had heard that root canal therapy was the most unpleasant dental treatment. ${ }^{4}$ In 2005, Chanpong et al. found that $12.4 \%$ of patients in their study were definitely interested in sedation or general anesthesia for their dental treatment, and $42.3 \%$ were interested depending upon cost. ${ }^{3}$ Among patients with high dental fear, $31.1 \%$ were definitely interested, with $54.1 \%$ being interested depending on cost. In the same year, Allen and Girdler reported that levels of anxiety regarding dental treatment were high, with $68 \%$ of patients in 
their study claiming some nervousness or worse, and $56 \%$ said they would like to have sedation if it were available. ${ }^{22}$ In summary, there might be more of a demand for sedation among patients than recognized by endodontic program directors, especially those in programs without IV-sedation training.

While 13 programs in our study offered IVsedation education to their residents, none of the programs required their residents to complete a minimum number of cases or experiences. This finding is in sharp contrast to the minimum Commission on Dental Accreditation (CODA) requirements for residents in oral and maxillofacial surgery programs. These programs are required to have their residents complete a minimum of 300 cases of general anesthesia/deep sedation in total, which must include a minimum of 50 pediatric patients. ${ }^{23}$

One interesting question is whether the program directors assessed correctly whether their residents were motivated to learn about IV-sedation. Only two of the 13 program directors agreed/strongly agreed that their residents were motivated to learn about IV-sedation. Research with dental school graduates concerning their desire for education about sedation seems to contradict this response in our study. In Moore et al.'s survey of dental school graduates from 2003 to $2007,44 \%$ of general dentists reported that a lack of training/experience or knowledge was a major reason for not offering sedation in their general dental practices, and the respondents' written comments indicated a desire for a greater number of clinical experiences involving sedation procedures in the predoctoral curriculum. ${ }^{24}$ In 2006, Boynes et al. assessed the quality and quantity of sedation education in U.S. dental schools among general dental practitioners who had graduated in 2003. ${ }^{19}$ Their responses also indicated a perceived need for sedation care by the majority of recent graduates and low overall satisfaction with the quality of sedation education in U.S. dental schools. The general consensus of most of those 2003 graduates was that they had gained little or no hands-on experience in sedation techniques and would have supported an increase in tuition and fees if an institution would offer more efficient sedation training. In 2007, Ryding and Murphy also found that about half of their respondents (52\%) believed that IV-sedation should be included in the treatment that a licensed dentist can provide. ${ }^{25}$ However, over $70 \%$ of their respondents believed that a separate license for the administration of IV-sedation should be required. In 2011, Fisher et al. found that the greatest perceived barrier to providing sedation was a lack of training (42\%). ${ }^{11}$ Most recently, in 2016, Oliver et al. reported that, in the United Kingdom, education on conscious sedation, both oral and intravenous, tended to be scored as either "deficient" or "wishing I had learned more" by $72 \%$ of their general dental practitioner respondents. ${ }^{20}$

While there has been research about IV-sedation education in dental schools, ${ }^{17,19,20}$ no study so far has inquired specifically how graduates from endodontic residency programs evaluate their education in this context. This might be partly due to the fact that the CODA standards for endodontic programs do not include a requirement that these graduates need to be competent to provide moderate IV-sedation. ${ }^{26}$ However, in 2012, Montagnese made a strong argument for moderate IV-sedation training in endodontic programs. ${ }^{6}$ In 2014, Setty et al. reported that because the postgraduate endodontic clinic at Case Western University saw pediatric patients on a fairly regular basis, the course director considered it important that residents became familiar and comfortable with various methods of behavior management, including sedation. ${ }^{13}$

To our knowledge, there has been no previous research concerning endodontists' thoughts about their education about IV-sedation. However, their perspectives can increase program directors' understanding of the importance of IV-sedation in the endodontic practices and for the demand of this adjunct procedure. Our survey of 616 endodontists found that the status quo concerning their education about IV-sedation was minimal: only $17 \%$ had received any classroom-based education, and only $9 \%$ had received any clinical training. It is therefore not surprising that only $10 \%$ agreed/strongly agreed that they had received adequate training in IV-sedation and that only $15 \%$ were overall satisfied with their training in IV-sedation. On the other hand, 23\% wished they had had more of this education, and $17 \%$ would like to take more continuing education classes about IV-sedation.

When we consider the effects of this low level of education and the lack of satisfaction with this education, it is also important to realize that only $25 \%$ of the respondents agreed/strongly agreed that they felt competent answering patients' questions about IV-sedation, and only $6 \%$ felt comfortable performing IV-sedation. These responses of practicing endodontists could not only inform program directors' curricular considerations in this context, but also showed that there is a clear opportunity and need for structured continuing dental education 
courses in the administration of IV-sedation. These courses could not only have didactic components, but should include clinical simulation with highfidelity mannequins to practice the administration of anesthetics, monitoring, and airway management.

One major limitation of this study is that use of the term "IV-sedation" might not have allowed a clear understanding of the specific considerations concerning the degree of sedation. The American Society of Anesthesiologists divides the level of sedation on a continuum of depth of sedation, from minimal sedation (anxiolysis), to moderate sedation/analgesia ("conscious sedation"), to deep sedation/analgesia, to general analgesia. ${ }^{27}$ Anxiolysis is a state in which the cognitive function and physical coordination may be impaired, but the patient will respond normally to verbal stimulation, and the airway, ventilatory, and cardiovascular functions are unaffected. Under moderate sedation, purposeful responses to verbal command or light tactile stimulation are maintained. Cardiovascular function as well as a patent airway is maintained, and spontaneous ventilation is adequate. Deep sedation is a level of sedation in which the patient is not easily aroused, but responds purposefully to repeated or painful stimulation. Cardiovascular functions are generally maintained, but intervention may be required to maintain respiratory function. General analgesia/anesthesia is reached when a patient is completely unconscious and not responsive to painful stimuli. Cardiovascular and respiratory functions are often compromised. By referring to the route of administration (IV-sedation), it is unclear which level of sedation the respondents considered. Using the term "moderate" IV-sedation would have allowed clearer interpretations of the responses.

\section{Conclusion}

In our study, the responses of directors of endodontic postgraduate programs showed a wide range of practices related to educating future endodontists about IV-sedation, with one program providing this education for the past 39 years, while a majority of programs did not offer any education. The hours of classroom-based education also differed widely from two to 60 hours among the programs that taught IVsedation to their students. Program directors who did offer this education agreed more strongly that there is a need for IV-sedation in endodontics and that future endodontists need to be able to provide IV-sedation than those directors whose programs did not offer this education. This difference in attitudes might explain why not all programs considered introducing IV-sedation education in the future. The survey of endodontists showed that they did not view their past education positively, that about a quarter of the respondents wanted more IV-sedation education, and that the majority did not feel competent even answering their patients' questions about IV-sedation.

\section{Acknowledgments}

This research was made possible by a grant from the Delta Dental Fund in Michigan and the University of Michigan Rackham Graduate School Fund to the first author. We want to thank the respondents for taking the time to respond to these surveys.

\section{REFERENCES}

1. American Dental Association. Guidelines for the use of sedation and general anesthesia by dentists. Chicago: American Dental Association, 2016.

2. Taani DSQ. Dental fear among a young adult Saudian population. Int Dent J 2001;51(2):62-6.

3. Chanpong B, Haas DA, Locker D. Need and demand for sedation or general anesthesia in dentistry: a national survey of the Canadian population. Anesth Prog 2005;52(1):3-11.

4. Wong M, Lytle WR. A comparison of anxiety levels associated with root canal therapy and oral surgery treatment. J Endod 1991;17(9):461-5.

5. Huh YK, Montagnese TA, Harding J, et al. Assessment of patients' awareness and factors influencing patients' demands for sedation in endodontics. J Endod 2015;41(2):182-9.

6. Montagnese TA. Why intravenous moderate sedation should be taught in graduate endodontic programs. J Dent Educ 2012;76(3):288-90.

7. Dionne RA, Gordon SM, McCullagh LM, Phero JC. Assessing the need for anesthesia and sedation in the general population. J Am Dent Assoc 1998;129(2):167-73.

8. Wood M. Intravenous ketamine and propofol in paediatric dental sedation: safe and effective? SAAD Dig 2013;29:31-9.

9. Olabi NF, Jones JE, Saxen MA, et al. The use of officebased sedation and general anesthesia by board certified pediatric dentists practicing in the United States. Anesth Prog 2012;59(1):12-7.

10. Tingey BT, Clark SH, Humbert LA, et al. Use of intravenous sedation in periodontal practice: a national survey. J Periodontol 2012;83(7):830-5.

11. Fisher V, Stassen LF, Nunn J. A survey to assess the provision of conscious sedation by general dental practitioners in the Republic of Ireland. J Ir Dent Assoc 2011;57(2): 99-106.

12. Ogle OE, Hertz MB. Anxiety control in the dental patient. Dent Clin North Am 2012;56(1):1-16.

13. Setty M, Montagnese TA, Baur D, et al. An analysis of moderate sedation protocols used in dental specialty programs: a retrospective observational study. J Endod 2014;40(9):1327-31. 
14. Leitch JA, Girdler NM. A survey of the teaching of conscious sedation in dental schools of the United Kingdom and Ireland. Br Dent J 2000;188(4):211-6.

15. Leitch J, Jauhar S. A follow-up survey of the teaching of conscious sedation in dental schools of the United Kingdom and Ireland. Anesth Prog 2006;53(2):43-8.

16. Scally KJ, Wilson KE, Girdler NM. A study of dental students' clinical knowledge acquisition and experiences in conscious sedation. Br Dent J 2015;218(6):351-4.

17. Morse Z, Sano K, Fujii K, Kanri T. Sedation in Japanese dental schools. Anesth Prog 2004;51(3):95-101.

18. Wilson S, Nathan JE. A survey study of sedation training in advanced pediatric dentistry programs: thoughts of program directors and students. Pediatr Dent 2011;33(4): 353-60.

19. Boynes SG, Lemak AL, Close JM. General dentists' evaluation of anesthesia sedation education in U.S. dental schools. J Dent Educ 2006;70(12):1289-93.

20. Oliver GR, Lynch CD, Chadwick BL, et al. What I wish I'd learned at dental school. Br Dent J 2016;221(4):187-94.

21. Hardigan PC, Succar CT, Fleisher JM. An analysis of response rate and economic costs between mail and webbased surveys among practicing dentists: a randomized trial. J Community Health 2012;37:383-94.
22. Allen EM, Girdler NM. Attitudes to conscious sedation in patients attending an emergency dental clinic. Prim Dent Care 2005;12(1):27-32.

23. Commission on Dental Accreditation. Accreditation standards for advanced specialty education programs in oral and maxillofacial surgery. Chicago: American Dental Association, 2015.

24. Moore PA, Boynes SG, Cuddy MA, et al. Educational experiences and preparedness in dental anesthesia: fiveyear outcome assessment and conclusions. J Dent Educ 2009;73(12):1379-86

25. Ryding HA, Murphy HJ. Use of nitrous oxide and oxygen for conscious sedation to manage pain and anxiety. J Can Dent Assoc 2007;73(8):711a-f.

26. Commission on Dental Accreditation. Accreditation standards for advanced specialty education programs in endodontics. Chicago: American Dental Association, 2008.

27. American Society of Anesthesiologists. Continuum of depth of sedation: definition of general anesthesia and levels of sedation/analgesia. At: file://C:/Users/mri/ Downloads/continuum-of-depth-of-sedation-definitionof-general-anesthesia-and-levels-of-sedation-analgesia \%20(2).pdf. Accessed 1 Dec. 2017. 